\title{
Analytical Investigation for In Situ Stress Measurement with Rheological Stress Recovery Method and Its Application
}

\author{
Quansheng Liu, ${ }^{1,2}$ Jingdong Jiang, ${ }^{1}$ Chengyuan Zhang, ${ }^{2}$ and Yuanguang Zhu' \\ ${ }^{1}$ School of Civil Engineering, Wuhan University, Wuhan 430072, China \\ ${ }^{2}$ State Key Laboratory of Geomechanics and Geotechnical Engineering, Institute of Rock and Soil Mechanics, \\ Chinese Academy of Sciences, Wuhan 430071, China
}

Correspondence should be addressed to Quansheng Liu; liuqs@whrsm.ac.cn

Received 10 October 2015; Revised 5 December 2015; Accepted 8 December 2015

Academic Editor: Marek Lefik

Copyright (C) 2016 Quansheng Liu et al. This is an open access article distributed under the Creative Commons Attribution License, which permits unrestricted use, distribution, and reproduction in any medium, provided the original work is properly cited.

\begin{abstract}
In situ stress is one of the most important parameters in underground engineering. Due to the difficulty and weakness of current stress measurement methods in deep soft rock, a new one, rheological stress recovery (RSR) method, to determine threedimensional stress tensor is developed. It is supposed that rock stresses will recover gradually with time and can be measured by embedding transducers into the borehole. In order to explore the relationship between the measured recovery stress and the initial stress, analytical solutions are developed for the stress measurement process with RSR method in a viscoelastic surrounding rock. The results showed that the measured recovery stress would be more close to the initial stress if the rock mass has a better rheological property, and the property of grouting material should be close to that of rock mass. Then, the RSR method, as well as overcoring technique, was carried out to measure the in situ stresses in Pingdingshan Number 1 coal mines in Henan Province, China. The stress measurement results are basically in the same order, and the major principal stresses are approximately in the direction of NW-SE, which correlates well with the stress regime of Pingdingshan zone known from the tectonic movement history.
\end{abstract}

\section{Introduction}

In situ stress is one of the most important parameters for designing stable underground structures and improving mining methods in deep soft rock. Rock stresses originate from gravity and tectonic forces and can only be inferred by drilling a borehole, making a slot and coring the rock [1]. A large number of stress measuring methods have been developed and a detailed summary of these techniques can be found in Amadei and Stephansson [2], Ljunggren et al. [3], Corthésy et al. [4], and Ulusay [5].

However, with the decrease of shallow coal resources in China, most of the key collieries have mined deep coal seams [6], the surrounding rocks of which tend to be soft and fragmentized. There exist limitations and measurement errors in common methods for stress measurement of soft rocks, and effective testing is very difficult.

Hydraulic fracturing (HF) can only determine the maximal and minimal principle stresses in a plane vertical to the borehole and is limited in highly anisotropic and fractured rock [7]. Although hydraulic tests on preexisting fractures (HTPF) can determine the 3D stress tensor by testing a large number of fractures along the borehole [8-10], it is not an efficient method due to its assumptions. Borehole relief method [11-13] would be strongly influenced by the stress path, constitutive law, and associated parameters in the interpretation of stress measurement [4]. Other stress measuring methods such as borehole breakout [14] and Kaiser effect [15], which estimate rock stresses based on the phenomenon relevant to stresses, have relatively low reliability and are controversial as a method to determine in situ stress. Anelastic strain recovery (ASR) method [16-18] requires orientated rock cores and is affected by a lot of factors (e.g., temperature variation, dehydration of samples, and accurate orientation) [19]. Therefore, it is important to develop a new method to measure in situ stress in deep soft rock.

A new method for in situ stress measurement in deep soft rocks, namely, rheological stress recovery (RSR) method, is proposed in this study. The advantages of this method are that it is simple, inexpensive, and 3D. The basic principles, testing 


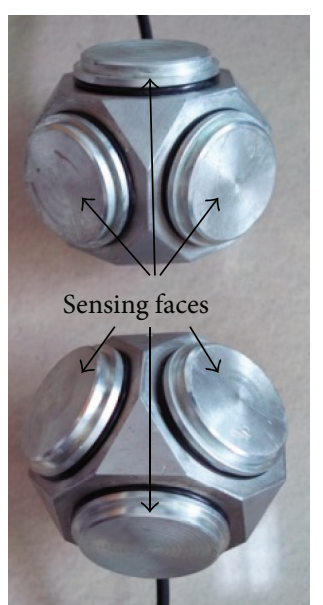

(a)

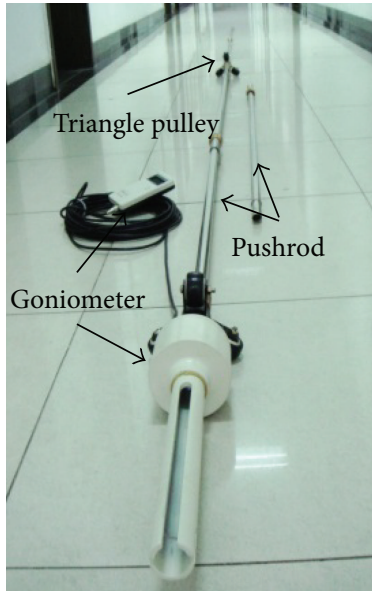

(b)

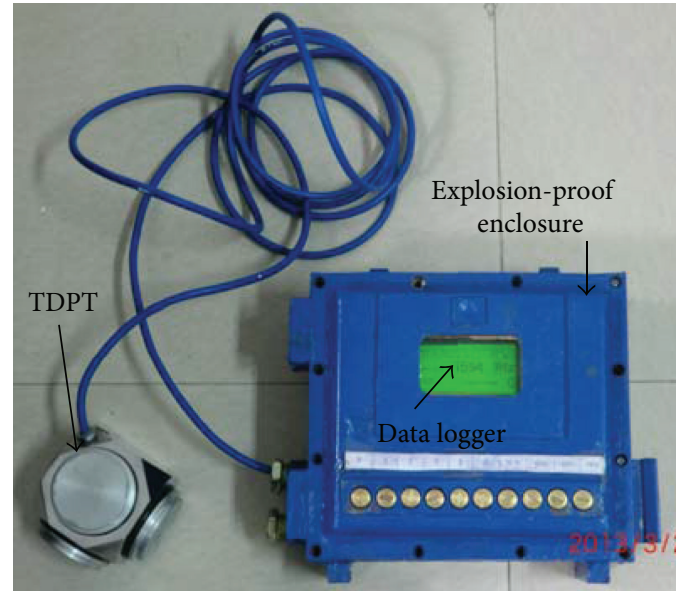

(c)

FIGURE 1: Test equipment of RSR method: (a) TDPTs, (b) pushrod and the goniometer, (c) explosion-proof data logger.

equipment, calculation equations, and related procedures of RSR method will be briefly introduced. Then, the measuring process is analyzed by analytical solutions to explore the applicability and accuracy of this method. Finally, the RSR method, as well as overcoring technique, was conducted in Pingdingshan Number 1 coal mine to measure both the in situ stress orientation and magnitude at a depth of $877 \mathrm{~m}$.

\section{An Outline of RSR Method}

2.1. Basic Principles. A large number of field monitoring and laboratory tests $[20,21]$ have shown that rheological properties of soft rocks are very significant under high geostress. Even for hard rock mass that is cut by several joints and fractures, creep deformation can also attain considerable magnitude [22]. Thus, a borehole will shrink gradually to be closed under high geostress due to the rheological characteristic of soft rocks and rock stresses will recover to the initial stress state with the growth of the time. Based on this, stress measurement with RSR method is proposed. It is supposed that rock stresses around the pressure transducers that are embedded in the borehole will recover gradually and eventually tend to be stable due to the rheological characteristics of surrounding rocks.

2.2. Main Equipment. The equipment used in this method involves pressure transducers, push rods with orientation device, and a data logger, shown in Figure 1. A threedimensional pressure transducer (TDPT), which can measure normal stresses in three directions, is developed for in situ stress measurement with RSR method (Figure 1(a)) and a test point needs two TDPTs in different directions. The TDPT, which contains three sensing faces (diameter $=58 \mathrm{~mm}$ ), is a waterproof cube structure (side length $=80 \mathrm{~mm}$ ) and suitable for a pressure up to $30 \mathrm{MPa}$. Vibrating wire force transducers are adopted on each sensing face due to the advantages of high accuracy and repeatability, possibility for remote measuring, digitalization of results, long service stability [23], and so forth. Eight corners of the TDPT have been cut out for the requirements of miniaturization. The pushrod is used to send the transducers to the test point and the rotation angles of the transducer are recorded by the goniometer in order to calculate the azimuth angle of each sensing face. The data logger is developed through explosion-proof design to meet the requirement of coal mine, shown in Figure 1(c).

2.3. Testing Procedures. The RSR method for measuring the stress in deep soft rocks comprises the following steps (Figure 2):

(1) A borehole is drilled till the test point in surrounding rocks of a soft rock tunnel.

(2) Stress transducers are fixed on a connecting rod and sent to the test point; a direction cosine of any two sensing faces in the normal direction is recorded and is not 1; a normal stress measuring device is mounted on each sensing face and connected with a data logger outside the borehole through long cables.

(3) Grouting is carried out on the drilling hole, and the borehole is sealed after being entirely filled.

(4) After the grout is solidified, pressure values are continually read from the data logger and six stress values are substituted into the calculation equations after the values are stable, so as to obtain 3D rock stress at the test point. With the adoption of this method, evolutional stress data of the test point can be also obtained. Moreover, the spatial variation and evolution of rock stress state can be measured through a series of pressure transducers embedded in different depth of the borehole.

2.4. Calculation Equations. A spatial coordinate system oxyz is established by taking normal directions of three mutually perpendicular sensing faces as directions of coordinate axes, and $x^{\prime}-, y^{\prime}-$, and $z^{\prime}$-axis are normal directions of 


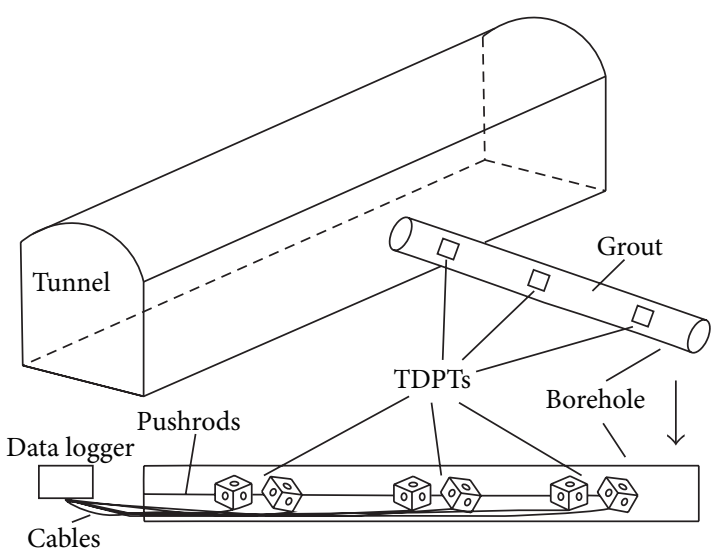

FIGURE 2: Sketch of stress measurement process with RSR method.

other sensing faces. $\sigma_{x}, \sigma_{y}, \sigma_{z}, \sigma_{x}^{\prime}, \sigma_{y}^{\prime}, \sigma_{z}^{\prime}$ are normal stresses measured by each sensing face, respectively. The stress state $\left(\sigma_{x}, \sigma_{y}, \sigma_{z}, \tau_{x y}, \tau_{y z}, \tau_{z x}\right)$ of the test point under the coordinate system oxyz can be calculated through

$$
\begin{aligned}
\sigma_{x}^{\prime}= & l_{1}^{2} \sigma_{x}+m_{1}^{2} \sigma_{y}+n_{1}^{2} \sigma_{z}+2 l_{1} m_{1} \tau_{x y}+2 m_{1} n_{1} \tau_{y z} \\
& +2 n_{1} l_{1} \tau_{z x}, \\
\sigma_{y}^{\prime}= & l_{2}^{2} \sigma_{x}+m_{2}^{2} \sigma_{y}+n_{2}^{2} \sigma_{z}+2 l_{2} m_{2} \tau_{x y}+2 m_{2} n_{2} \tau_{y z} \\
& +2 n_{2} l_{2} \tau_{y z}, \\
\sigma_{z}^{\prime}= & l_{3}^{2} \sigma_{x}+m_{3}^{2} \sigma_{y}+n_{3}^{2} \sigma_{z}+2 l_{3} m_{3} \tau_{x y}+2 m_{3} n_{3} \tau_{y z} \\
& +2 n_{3} l_{3} \tau_{y z},
\end{aligned}
$$

where $\tau_{x y}, \tau_{y z}$, and $\tau_{z x}$ are shear stress components under the coordinate system oxyz; $l_{1}, l_{2}$, and $l_{3}$, respectively, represent direction cosines between $x^{\prime}-, y^{\prime}$-, and $z^{\prime}$-axis and $x$-axis; $m_{1}, m_{2}$, and $m_{3}$, respectively, represent direction cosines between $x^{\prime}-, y^{\prime}$-, and $z^{\prime}$-axis and $y$-axis; and $n_{1}, n_{2}$, and $n_{3}$, respectively, represent direction cosines between $x^{\prime}-, y^{\prime}$-, and $z^{\prime}$-axis and $z$-axis.

\section{Definition of the Problem}

In this paper, a two-dimensional model of the stress measurement process is conducted to determine the recovery stress on the pressure transducer. The transducer, which is adhered to the borehole by elastic grout layer, is thought to be hollow and elastic. The cross sections of the transducer, grout layer, and the borehole are circular and concentric, shown in Figure 3. The interfaces between the rock and the grout layer and between the grout layer and the transducer are assumed to be smooth. The surrounding rocks are homogeneous, isotropic, and linearly viscoelastic and the lateral pressure coefficient is $\lambda$.

Regarding the above assumptions, the problem is considered as a two-dimensional (2D) infinite viscoelastic plane subjected to a biaxial stress, which treats a geometrically similar problem with tunnel linings in circular tunnels

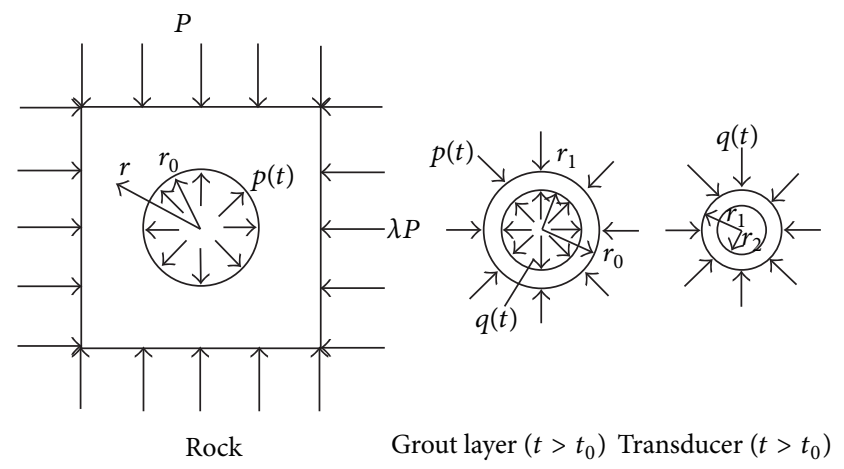

FIGURE 3: Illustration of the radii of the grout layer and the transducer.

$[24,25]$. The process of stress measurement can be divided into two stages. During the first stage spanning from borehole excavation until the time, at $t=t_{0}$, pressure of the surrounding rock is released and there is no pressure on the grout layer and the transducer. The second stage spans from the time of the solidification of the grout, at $t=t_{0}$, onwards. The contact pressures between the rock and the grout layer and between the grout layer and the transducer, which will vary with time, are assumed as $p(t)$ and $q(t)$, respectively.

For such a biaxial plane strain condition, a cylindrical coordinate system $(r, \theta, z)$ is employed and the in situ stress at infinity $(r=\infty)$ can be written as follows:

$$
\begin{aligned}
\sigma_{r} & =\frac{P}{2}[(1+\lambda)+(1-\lambda) \cos 2 \theta], \\
\sigma_{\theta} & =\frac{P}{2}[(1+\lambda)-(1-\lambda) \cos 2 \theta], \\
\tau_{r \theta} & =-\frac{P}{2}(1-\lambda) \sin 2 \theta,
\end{aligned}
$$

where $\sigma_{r}$ is the radial stress of the rock, $\sigma_{\theta}$ is the hoop stress of the rock, $\tau_{r \theta}$ is the shear stress of the rock, and $P$ is the vertical in situ stress.

The in situ stress can be divided into two parts: uniform part and nonuniform part. Correspondingly, the contact pressures on the interfaces can also be divided into uniform part and nonuniform part:

$$
\begin{aligned}
& p(t)=p_{0}(t)+p_{1}(t) \cos 2 \theta \\
& q(t)=q_{0}(t)+q_{1}(t) \cos 2 \theta
\end{aligned}
$$

where $p_{0}(t)$ and $q_{0}(t)$ are contact stresses under uniform in situ stress and $p_{1}(t) \cos 2 \theta$ and $q_{1}(t) \cos 2 \theta$ are contact stresses under nonuniform in situ stress.

After the grout is solidified $\left(t>t_{0}\right)$, the boundary condition for this problem is

$$
\begin{aligned}
& u_{r c}\left(r_{0}, t\right)=u_{r}\left(r_{0}, t\right), \\
& u_{r T}\left(r_{1}, t\right)=u_{r c}\left(r_{1}, t\right),
\end{aligned}
$$

where $u_{r}, u_{r c}$, and $u_{r T}$ are the radial displacements in the rock, the grout layer, and the transducer, respectively; $r_{0}$ is 
the radius of the borehole; and $r_{1}$ is the external radius of the transducer.

\section{Solution for the Problem}

4.1. The Forms of Solution in Laplace Domain under Uniform Stress Field. According to the correspondence principle, the viscoelastic displacement of the rock under uniform in situ stress $(P(1+\lambda) / 2)$ at the borehole wall $\left(r=r_{0}\right)$ can be written as $[24,26]$

$$
u_{P 0}\left(r_{0}, t\right)=\frac{P r_{0}}{4}(1+\lambda) J(t),
$$

where $J(t)$ is the shear creep compliance and will be described in more detail below.

The radial displacement of the rock under uniform in situ stress after time $t_{0}$ is

$$
\Delta u_{P 0}\left(r_{0}, t\right)=\frac{1+\lambda}{4} \operatorname{Pr}_{0} \Delta J,
$$

where $\Delta J=J\left(t+t_{0}\right)-J\left(t_{0}\right)$.

After time $t_{0}$, contact pressures exist on the interface between the rock and the grout layer. Then, the total radial displacement of the rock at the borehole wall $\left(r=r_{0}\right)$ can be written as

$$
u_{r 0}\left(r_{0}, t\right)=\frac{1+\lambda}{4} P r_{0} \Delta J-\frac{p_{0}(t) r_{0}}{2 G_{0}},
$$

where $G_{0}$ is the shear modulus of the rock.

The Laplace transform of a function, $f(t)$, is defined as

$$
\bar{f}(s)=\int_{0}^{\infty} f(t) e^{-s t} d t,
$$

where $s$ is the transform parameter, and the inverse Laplace transform is expressed by

$$
L^{-1}[\bar{f}(s)]=f(t)=\frac{1}{2 \pi i} \int_{\beta-i \infty}^{\beta+i \infty} \bar{f}(s) e^{s t} d t .
$$

The Laplace transform of (7) gives rise to

$$
\bar{u}_{r 0}\left(r_{0}, t\right)=\frac{1+\lambda}{4} \operatorname{Pr}_{0} \Delta \bar{J}-\frac{\bar{p}_{0}(s) r_{0}}{2 \bar{G}_{0}(s)} .
$$

The grout layer is thought to be linear elastic and $G_{c}$, $\mu_{c}$ are the shear modulus and Poisson's ratio, respectively. The radial displacements of the grout layer under contact pressures $\left(p_{0}(t)\right.$ and $\left.q_{0}(t)\right)$ in the Laplace domain, at $r=r_{0}$ and $r=r_{1}$, are

$$
\begin{aligned}
& \bar{u}_{c 0}\left(r_{0}, s\right)=\frac{\bar{p}_{0}(s) r_{0}}{2 G_{c}} m_{c 0}-\frac{\bar{q}_{0}(s) r_{0}}{2 G_{c}} n_{c 0}, \\
& \bar{u}_{c 0}\left(r_{1}, s\right)=\frac{\bar{p}_{0}(s) r_{0}}{2 G_{c}} m_{c 0}^{\prime}-\frac{\bar{q}_{0}(s) r_{0}}{2 G_{c}} n_{c 0}^{\prime},
\end{aligned}
$$

where

$$
\begin{aligned}
& m_{c 0}=\frac{r_{1}^{2}+\left(1-2 \mu_{c}\right) r_{0}^{2}}{r_{0}^{2}-r_{1}^{2}}, \\
& n_{c 0}=\frac{r_{1}^{2}\left(2-2 \mu_{c}\right)}{r_{0}^{2}-r_{1}^{2}},
\end{aligned}
$$

$$
\begin{aligned}
& m_{c 0}^{\prime}=\frac{r_{0}^{2}\left(2-2 \mu_{c}\right)}{r_{0}^{2}-r_{1}^{2}}, \\
& n_{c 0}^{\prime}=\frac{r_{0}^{2}+\left(1-2 \mu_{c}\right) r_{1}^{2}}{r_{0}^{2}-r_{1}^{2}}
\end{aligned}
$$

are constant coefficients of parameters $r_{0}, r_{1}$, and $\mu_{c}$.

The radial displacement of the transducer on the interfaces between the grout layer and the transducer $\left(r=r_{1}\right)$ in Laplace domain is

$$
\bar{u}_{T 0}\left(r_{1}, s\right)=\frac{\bar{q}_{0}(s) r_{1}}{2 G_{T}} m_{T 0},
$$

where $G_{T}, \mu_{T}$ are the shear elastic modulus and Poisson's ratio of the transducer, respectively, and

$$
m_{T 0}=\frac{r_{2}^{2}+\left(1-2 \mu_{T}\right) r_{1}^{2}}{r_{1}^{2}-r_{2}^{2}}
$$

is a constant coefficient of parameters $r_{1}, r_{2}$, and $\mu_{T}$.

4.2. The Forms of Solution in Laplace Domain under Nonuniform Stress Field. To simplify the solution of this problem, the Poisson's ratio of the rock $\mu_{0}$ is assumed to be a constant and then the total radial displacement of the rock under nonuniform stress field at the borehole wall $\left(r=r_{0}\right)$ in the Laplace domain is

$$
\begin{aligned}
\bar{u}_{r 1}\left(r_{0}, s\right)= & \frac{1-\lambda}{4}\left(3-4 \mu_{0}\right) \operatorname{Pr}_{0} \Delta \bar{J} \\
& -\frac{\bar{p}_{1}(s) r_{0}}{6 \bar{G}_{0}(s)}\left(5-6 \mu_{0}\right) \cos 2 \theta .
\end{aligned}
$$

The Laplace transform of the radial displacement of the grout layer on the interface $\left(r=r_{0}\right.$ and $\left.r=r_{1}\right)$ under nonuniform contact pressures can be written as

$$
\begin{aligned}
& \bar{u}_{c 1}\left(r_{0}, s\right)=\frac{\bar{p}_{1}(s) r_{0}}{2 G_{c}} m_{c 1} \cos 2 \theta-\frac{\bar{q}_{1}(s) r_{0}}{2 G_{c}} n_{c 1} \cos 2 \theta, \\
& \bar{u}_{c 1}\left(r_{1}, s\right)=\frac{\bar{p}_{1}(s) r_{1}}{2 G_{c}} m_{c 1}^{\prime} \cos 2 \theta-\frac{\bar{q}_{1}(s) r_{1}}{2 G_{c}} n_{c 1}^{\prime} \cos 2 \theta .
\end{aligned}
$$

Define

$$
\begin{aligned}
& m_{c 1}=f_{c 1}-f_{c 5} r_{0}^{-4}+2 \mu_{c} f_{c 3} r_{0}^{2}-2\left(1-\mu_{c}\right) f_{c 7} r_{0}^{-2}, \\
& n_{c 1}=f_{c 2}-f_{c 6} r_{0}^{-4}+2 \mu_{c} f_{c 4} r_{0}^{2}-2\left(1-\mu_{c}\right) f_{c 8} r_{0}^{-2}, \\
& m_{c 1}^{\prime}=f_{c 1}-f_{c 5} r_{1}^{-4}+2 \mu_{c} f_{c 3} r_{1}^{2}-2\left(1-\mu_{c}\right) f_{c 7} r_{1}^{-2}, \\
& n_{c 1}^{\prime}=f_{c 2}-f_{c 6} r_{1}^{-4}+2 \mu_{c} f_{c 4} r_{1}^{2}-2\left(1-\mu_{c}\right) f_{c 8} r_{1}^{-2},
\end{aligned}
$$$$
\begin{aligned}
& f_{c 1}=\frac{r_{0}^{6}+r_{0}^{4} r_{1}^{2}+2 r_{0}^{2} r_{1}^{4}}{\left(r_{0}^{2}-r_{1}^{2}\right)^{3}}, \\
& f_{c 2}=\frac{2 r_{0}^{4} r_{1}^{2}+r_{0}^{2} r_{1}^{4}+r_{1}^{6}}{\left(r_{0}^{2}-r_{1}^{2}\right)^{3}},
\end{aligned}
$$ 


$$
\begin{aligned}
& f_{c 3}=-\frac{r_{0}^{4}+3 r_{0}^{2} r_{1}^{2}}{3\left(r_{0}^{2}-r_{1}^{2}\right)^{3}}, \\
& f_{c 4}=-\frac{3 r_{0}^{2} r_{1}^{2}+r_{1}^{4}}{3\left(r_{0}^{2}-r_{1}^{2}\right)^{3}}, \\
& f_{c 5}=\frac{3 r_{0}^{6} r_{1}^{4}+r_{0}^{4} r_{1}^{6}}{3\left(r_{0}^{2}-r_{1}^{2}\right)^{3}}, \\
& f_{c 6}=\frac{r_{0}^{6} r_{1}^{4}+3 r_{0}^{4} r_{1}^{6}}{3\left(r_{0}^{2}-r_{1}^{2}\right)^{3}}, \\
& f_{c 7}=-\frac{2 r_{0}^{6} r_{1}^{2}+r_{0}^{4} r_{1}^{4}+r_{0}^{2} r_{1}^{6}}{\left(r_{0}^{2}-r_{1}^{2}\right)^{3}}, \\
& f_{c 8}=-\frac{r_{0}^{6} r_{1}^{2}+r_{0}^{4} r_{1}^{4}+2 r_{0}^{2} r_{1}^{6}}{\left(r_{0}^{2}-r_{1}^{2}\right)^{3}} .
\end{aligned}
$$

The Laplace transform of the radial displacement of the transducer on the interface $\left(r=r_{1}\right)$ under nonuniform contact pressure is expressed as follows:

$$
\bar{u}_{T 1}\left(r_{1}, s\right)=\frac{\bar{q}_{1}(s) r_{1}}{2 G_{T}} m_{T 1} \cos 2 \theta,
$$

where

$$
m_{T 1}=f_{T 1}-f_{T 3} r_{1}^{-4}+2 \mu_{T} f_{T 2} r_{1}^{2}-2\left(1-\mu_{T}\right) f_{T 4} r_{1}^{-2}
$$

with

$$
\begin{aligned}
& f_{T 1}=\frac{r_{1}^{6}+r_{1}^{4} r_{2}^{2}+2 r_{1}^{2} r_{2}^{4}}{\left(r_{1}^{2}-r_{2}^{2}\right)^{3}}, \\
& f_{T 2}=-\frac{r_{1}^{4}+3 r_{1}^{2} r_{2}^{2}}{3\left(r_{1}^{2}-r_{2}^{2}\right)^{3}}, \\
& f_{T 3}=\frac{3 r_{1}^{6} r_{2}^{4}+r_{1}^{4} r_{2}^{6}}{3\left(r_{1}^{2}-r_{2}^{2}\right)^{3}}, \\
& f_{T 4}=-\frac{2 r_{1}^{6} r_{2}^{2}+r_{1}^{4} r_{2}^{4}+r_{1}^{2} r_{2}^{6}}{\left(r_{1}^{2}-r_{2}^{2}\right)^{3}} .
\end{aligned}
$$

4.3. Determination of the Contact Pressures. According to the boundary condition (4), the boundary compatibility conditions in the Laplace domain are

$$
\begin{aligned}
& \bar{u}_{r 0}\left(r_{0}, s\right)=\bar{u}_{c 0}\left(r_{0}, s\right), \\
& \bar{u}_{r 1}\left(r_{0}, s\right)=\bar{u}_{c 1}\left(r_{0}, s\right), \\
& \bar{u}_{c 0}^{\prime}\left(r_{1}, s\right)=\bar{u}_{T 0}\left(r_{1}, s\right), \\
& \bar{u}_{c 1}^{\prime}\left(r_{1}, s\right)=\bar{u}_{T 1}\left(r_{1}, s\right) .
\end{aligned}
$$

Submitting (10)-(18) into (21), the following can be obtained:

$$
\begin{aligned}
& \bar{p}_{0}(s)=\frac{\Delta \bar{J}}{1 / \bar{G}_{0}(s)+\left(\left(G_{T} m_{c 0} n_{c 0}^{\prime}-G_{T} n_{c 0} m_{c 0}^{\prime}+G_{c} m_{T 0} m_{c 0}\right) /\left(G_{T} n_{c 0}^{\prime}+G_{c} m_{T 0}\right) G_{c}\right)} \cdot \frac{1+\lambda}{2} P \\
& \bar{q}_{0}(s)=\frac{\Delta \bar{J}}{\left(\left(G_{T} G_{c} n_{c 0}^{\prime}+G_{c}^{2} m_{T 0}\right) / G_{T} G_{c} m_{c 0}^{\prime}\right)\left(1 / \bar{G}_{0}(s)\right)+\left(\left(G_{T} m_{c 0} n_{c 0}^{\prime}-G_{T} n_{c 0} m_{c 0}^{\prime}+G_{c} m_{T 0} m_{c 0}\right) / G_{T} G_{c} m_{c 0}^{\prime}\right)} \cdot \frac{1+\lambda}{2} P \\
& \bar{p}_{1}(s)=\frac{\left(3-4 \mu_{0}\right) \Delta \bar{J}}{\left(\left(5-6 \mu_{0}\right) / 3\right)\left(1 / \bar{G}_{0}(s)\right)+\left(\left(G_{T} m_{c 1} n_{c 1}^{\prime}-G_{T} n_{c 1} m_{c 1}^{\prime}+G_{c} m_{T 1} m_{c 1}\right) /\left(G_{T} n_{c 1}^{\prime}+G_{c} m_{T 1}\right) G_{c}\right)} \cdot \frac{1-\lambda}{2} P, \\
& \bar{q}_{1}(s)=\frac{\left(3-4 \mu_{0}\right) \Delta \bar{J}}{\left(\left(G_{T} n_{c 1}^{\prime}+G_{c} m_{T 1}\right) / G_{T} m_{c 1}^{\prime}\right)\left(\left(5-6 \mu_{0}\right) / 3\right)\left(1 / \bar{G}_{0}(s)\right)+\left(\left(G_{T} m_{c 1} n_{c 1}^{\prime}-G_{T} n_{c 1} m_{c 1}^{\prime}+G_{c} m_{T 1} m_{c 1}\right) / G_{T} G_{c} m_{c 1}^{\prime}\right)} \\
& . \frac{1-\lambda}{2} P .
\end{aligned}
$$

4.4. Analytical Solution for 3-Parameter Solid Model. For the time-dependent behavior of soft or highly jointed rock mass or rock mass with high in situ stress, the 3-parameter solid model may be commonly employed, as shown in Figure 4, the shear creep compliance is written as where $G_{1}, G_{2}$ are the shear moduli and $\eta$ is the viscosity coefficients.

The differential equation of 3-parameter solid model can be written as

$$
J(t)=\frac{1}{G_{1}}+\frac{1}{G_{2}}\left(1-\exp \left(-\frac{G_{2} t}{\eta}\right)\right),
$$

$$
1+P_{3} \dot{\tau}=Q_{3} \gamma+Q_{4} \dot{\gamma}
$$




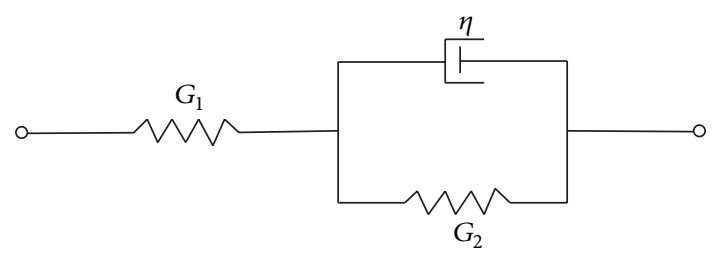

FIGURE 4: Sketch of 3-parameter solid model.

where

$$
\begin{aligned}
P_{3} & =\frac{\eta}{G_{1}+G_{2}}, \\
Q_{3} & =\frac{G_{1} G_{2}}{G_{1}+G_{2}}, \\
Q_{4} & =\frac{\eta G_{1}}{G_{1}+G_{2}} .
\end{aligned}
$$

Then, the contact pressure on the transducer can be obtained:

$$
\begin{array}{r}
q(t)=q_{0}(t)+q_{1}(t) \cos 2 \theta=\frac{1+\lambda}{2} P\left(1-\frac{G_{\infty}}{G_{\text {ini }}}\right) \\
. \frac{\exp \left(-G_{2} t_{0} / \eta\right)}{R_{1}+G_{\infty} R_{2}}\left(1-\exp \left(-\frac{R_{1}+Q_{3} R_{2}}{P_{3} R_{1}+Q_{4} R_{2}} t\right)\right) \\
+\frac{1-\lambda}{2}\left(3-4 \mu_{0}\right) P\left(1-\frac{G_{\infty}}{G_{\text {ini }}}\right) \\
. \frac{\exp \left(-G_{2} t_{0} / \eta\right)}{R_{3}+G_{\infty} R_{4}}\left(1-\exp \left(-\frac{R_{3}+Q_{3} R_{4}}{P_{3} R_{3}+Q_{4} R_{4}} t\right)\right)
\end{array}
$$$$
\cdot \cos 2 \theta
$$

where $G_{\infty}=G_{1} G_{2} /\left(G_{1}+G_{2}\right)$ is the long-term shear modulus, $G_{\text {ini }}=G_{1}$ is the initial shear modulus, and

$$
\begin{aligned}
& R_{1}=\frac{G_{T} n_{c 0}^{\prime}+G_{c} m_{T 0}}{G_{T} m_{c 0}^{\prime}}, \\
& R_{2}=\frac{G_{T} n_{c 1}^{\prime}+G_{c} m_{T 1}}{G_{T} m_{c 1}^{\prime}} \frac{5-6 \mu_{0}}{3}, \\
& R_{3}=\frac{G_{T} m_{c 0} n_{c 0}^{\prime}-G_{T} n_{c 0} m_{c 0}^{\prime}+G_{c} m_{T 0} m_{c 0}}{G_{T} G_{c} m_{c 0}^{\prime}}, \\
& R_{4}=\frac{G_{T} m_{c 1} n_{c 1}^{\prime}-G_{T} n_{c 1} m_{c 1}^{\prime}+G_{c} m_{T 1} m_{c 1}}{G_{T} G_{c} m_{c 1}^{\prime}} .
\end{aligned}
$$

Paying attention to the analytical expression derived for the contact pressure on the transducer $(q(t))$ for 3-parameter solid model instead, it can be found that the stable contact pressure on the transducer $(q(\infty))$ is dependent mainly on the mechanical properties of the rock mass, the solidification time of the grout $\left(t_{0}\right)$, and the shear moduli of the grout layer, as shown in (26). With the decrease of the longterm shear modulus of the rock, the contact pressure on the

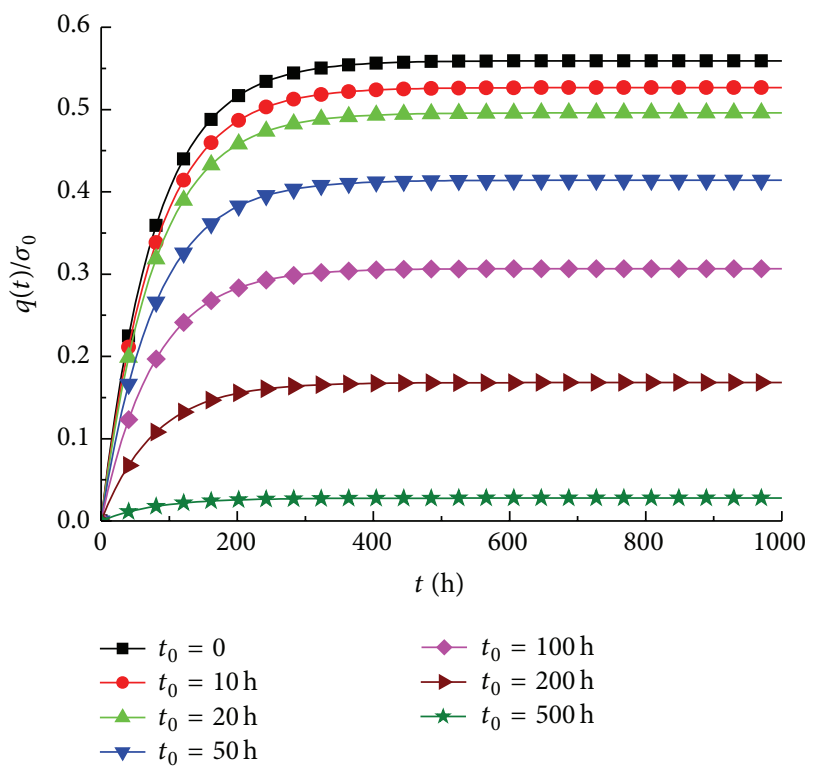

Figure 5: The ratio of the contact pressure $(q(t))$ on the transducer to the in situ stress calculated at $\theta=0^{\circ}$ for various solidification times.

transducer increases. In order to expound the effects of the grout solidification time $\left(t_{0}\right)$, the shear moduli of the grout, and the properties of the rock mass on the contact pressures $(q(t))$, parametric investigations have been presented here.

Regarding the geometrical properties of this problem, we have $r_{0}=65 \mathrm{~mm}, r_{1}=55 \mathrm{~mm}, r_{2}=50 \mathrm{~mm}, P=1 \mathrm{MPa}$, and $\lambda=1.2$. The values of the mechanical properties are $G_{c}=$ $4 \mathrm{GPa}, \mu_{c}=0.35, G_{T}=80 \mathrm{GPa}$, and $\mu_{T}=0.25$. According to the experiment tests and back analysis $[20,25]$, the following values can be assumed: $G_{1}=2576 \mathrm{MPa}, G_{2}=1903 \mathrm{MPa}, \eta=$ 3.167e $5 \mathrm{MPa} \cdot \mathrm{h}$, and $\mu_{0}=0.35$ for 3 -parameter solid model. For the sake of explanation, the ratio of the contact pressure to the in situ stress will be presented in Figures 5, 6, and 7.

The solidification time of the grout is assumed to be seven values: $0,10 \mathrm{~h}, 20 \mathrm{~h}, 50 \mathrm{~h}, 100 \mathrm{~h}, 200 \mathrm{~h}$, and $500 \mathrm{~h}$. The general trend is that the contact pressures increase gradually and reach stability after a period of time.

In Figure 5, it can be found that the contact pressures on the transducer develop to be stable over time. When the solidification time increases, the ratio of the stable contact pressure to the in situ stress decreases from $60 \%$ to 0 . Thus, it can be concluded that the less solidification time will be beneficial for the recovery of the contact pressure on the transducer.

4.5. Influence of the Shear Modulus of the Grout Material. The shear modulus of the transducer is a fixed value of $80 \mathrm{GPa}$. Nine values of the modulus of the grout material $\left(G_{c}\right)$ are selected and the transducer-grout modulus ratios are $1: 1,2: 1$, $5: 1,10: 1,25: 1,50: 1,100: 1,200: 1$, and $500: 1$, respectively. The influence of the shear modulus of the grout material is analyzed for a solidification time of $t_{0}=10 \mathrm{~h}$.

In Figure 6, the results of the ratio of the contact pressures $(q(t))$ on the transducer to the in situ stress calculated at 


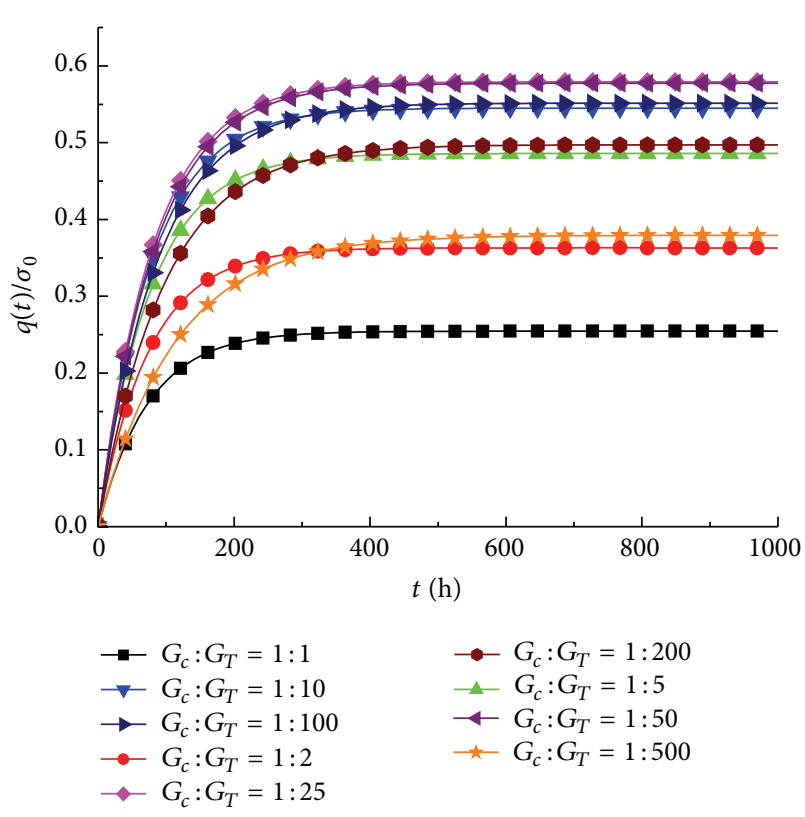

(a)

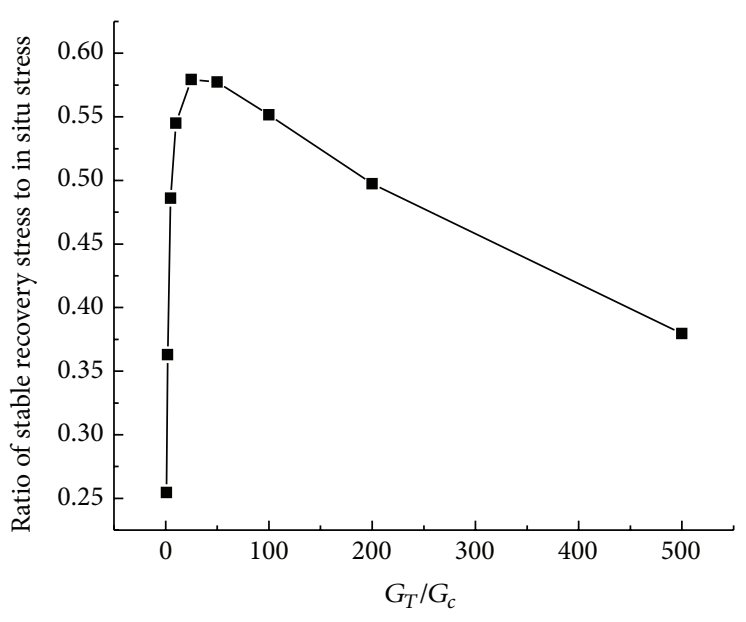

(b)

Figure 6: Results for different shear moduli of the grout material: (a) ratio of the contact pressure $(q(t))$ to in situ stress, (b) ratio of stable recovery stress to in situ stress.

$\theta=0^{\circ}$ with different shear moduli of the grout material are plotted. It can be found that the contact pressure increases gradually and reaches stability after a period of time, and the ratio of the stable recovery pressure on the transducer to the in situ stress first increases and then decreases with the increase of transducer-grout modulus ratio, as shown in Figure 6. When the transducer-grout modulus ratio is between $20: 1$ and $50: 1$, the stable recovery pressure on the transducer reaches the maximum value (about $60 \%$ of the in situ stress). From these figures, it emerges that suitable grout material is important for transducers to achieve optimal stresses. The type of the grout material should be determined after the mix proportion test before field application. The grout material used in the field test should have good mechanical properties and are made into samples to measure the mechanical parameters in the lab. Moreover, it is essential to carry out calibration tests for the transducer using different grouting materials before its field application.

4.6. Influence of the Properties of the Rock Mass. To illustrate the influence of the properties of the rock mass on the recovery stresses measured by the transducer, an example is presented herein. The properties of the grouting material are assumed to be the same with that of rock masses. The shear modulus $G_{1}$ is fixed and $G_{2}$ are assumed to be six different values, and the ratio of the initial modulus $G_{\text {ini }}$ to the longterm modulus $G_{\infty}$ is $1.2,1.5,2,3,5,11,21$, and 51 , accordingly. The results have been shown in Figure 7.

In Figure 7(a), it can be found that the recovery stresses measured by the transducer increase gradually and reach stability after a period of time. From Figure 7(b), with the reduction of the long-term modulus $G_{\infty}$, that is, the increase of the modulus ratio $G_{0} / G_{\infty}$, the final recovery stress increases. When the modulus ratio is greater than 10 , the final recovery stress gradually turns to be stable and is above $90 \%$ of the initial stress. From the figures, it emerges that if the rock mass has a better rheological property, the recovery stress measured by the transducer is more close to the initial stress. Moreover, in practical measurement, the final recovery ratio can be obtained from the initial long-term modulus ratio $G_{0} / G_{\infty}$ which can be calculated through creep experiment of rock masses according to the curves in Figure 7(b), and the in situ stress can be evaluated from the final recovery ratio and the practical measured recovery stresses.

\section{Field Test}

The in situ stress measurements were carried out in Pingdingshan Number 1 coal mine, situated in Henan Province, northern China, as shown in Figure 8. The Pingdingshan coalfield is about $38 \mathrm{~km}$ long E-W and $20 \mathrm{~km}$ wide N$\mathrm{S}$, and the coal-bearing sediments are mostly of Permian age, mainly comprising sandstone, sandy mudstone, and carbonaceous shale besides coals, which are overlain by the Tertiary and Quaternary deposits [27]. The general structural configuration of Pingdingshan coal mine is a series of NW folds in which the major one is Likou syncline. It is a broad and gentle fold, appearing as a brush structure converging to the southeast and diverging to the northwest. There are some other secondary folds in this area, for example, Guozhuang anticline, Niuzhuang syncline, and Zhugemiao anticline in the south of Likou syncline and Baishigou anticline, Lingwushan syncline, and Xiangxia fault in the north of Likou syncline. 


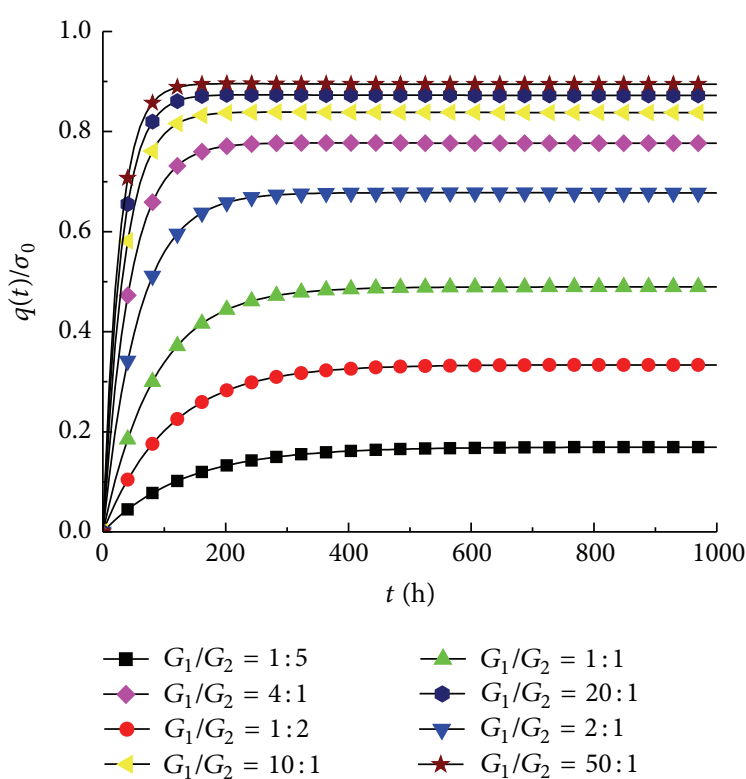

(a)

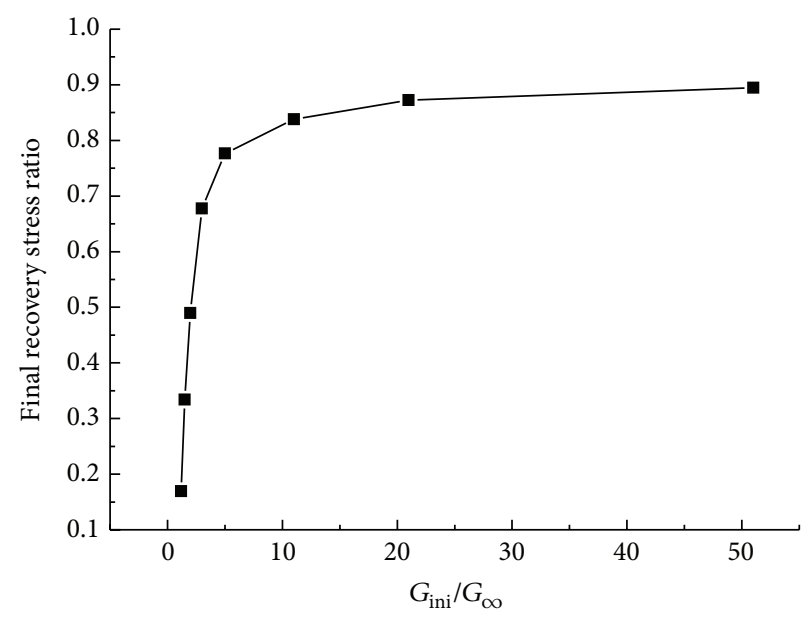

(b)

FIGURE 7: Results for different rock properties: (a) ratio of the contact pressure $(q(t))$ to in situ stress, (b) ratio of stable recovery stress to in situ stress.

TABLE 1: In situ stress magnitudes by overcoring technique using different elastic parameters at the horizontal borehole.

\begin{tabular}{|c|c|c|c|c|c|c|c|c|c|c|}
\hline \multicolumn{2}{|c|}{ Parameter } & \multicolumn{3}{|c|}{$\sigma_{1}$} & \multicolumn{3}{|c|}{$\sigma_{2}$} & \multicolumn{3}{|c|}{$\sigma_{3}$} \\
\hline$E(\mathrm{GPa})$ & $v$ & Magnitude (MPa) & Azimuth $\left(^{\circ}\right)$ & $\operatorname{Dip}\left({ }^{\circ}\right)$ & Magnitude (MPa) & Azimuth $\left(^{\circ}\right)$ & $\operatorname{Dip}\left({ }^{\circ}\right)$ & Magnitude (MPa) & Azimuth $\left(^{\circ}\right)$ & $\operatorname{Dip}\left({ }^{\circ}\right)$ \\
\hline 5 & 0.31 & 22.92 & 145.56 & 4.45 & 18.29 & 331.99 & 85.53 & 15.01 & 235.59 & 0.50 \\
\hline 8 & 0.31 & 34.45 & 143.15 & 5.07 & 27.20 & 348.27 & 84.40 & 22.66 & 233.36 & 2.37 \\
\hline
\end{tabular}

The test site of Pingdingshan Number 1 coal mine is located at a track-dip tunnel with a vertical buried depth of about $877 \mathrm{~m}$, the lithology of which is dark gray sandy mudstone. The in situ stress measurements were carried out in both horizontal and vertical boreholes with $30 \mathrm{~m}$ in depth and $130 \mathrm{~mm}$ in diameter. The sketch of borehole layout is shown in Figure 9. The horizontal borehole was inclined to the horizontal plane at $10^{\circ}$. Before the application of the RSR method, overcoring technique was carried out in the horizontal borehole according to the ISTM standard [28]. After overcoring, the rock core including the hollow inclusion gauge was calibrated in the calibration instrument. In order to obtain the mechanical parameters more accurately, rock cores drilled from the testing borehole were prepared into standard specimens with $50 \mathrm{~mm}$ in diameter and $100 \mathrm{~mm}$ in length. The elastic parameters were determined by several specimens from uniaxial compression experiment in lab. Then, the TDPTs were installed at the overcoring position according to the testing procedures of RSR method. The appropriate grouting materials were selected after a mix design in the lab to make the property of grouting materials close to that of rock masses.

\section{Results and Discussion}

The overcoring test was first finished in horizontal borehole at Number 1 coal mine and the curves of microstrain values versus the overcoring depth were given in Figure 10. Based on the test of elastic parameters of rock mass, the elastic modulus varies in a range $(5 \mathrm{GPa} \sim 8 \mathrm{GPa})$, and the calculated in situ stresses using different elastic modulus are shown in Table 1. It can be found that the magnitudes of three principal stress components increase as elastic modulus $E$ increases, whereas their azimuth and dip angles are maintained nearly the same. Ge and Hou [29] have found that when Poisson's ratio $v$ is constant, the magnitudes of three principal stresses will increase (or decrease) with the increase (or decrease) of $E$. Therefore, the principal stress magnitudes of overcoring technique vary in a range.

The monitor of the recovery stresses using TDPTs and temperature changes in both horizontal and vertical boreholes at Pingdingshan Number 1 coal mine has been recorded for a period of about 500 days. It should be noted that the calibration coefficients of each sensing face were determined by calibration test using the actual grouting material, and the influence of the environmental temperature on the transducer is analyzed and compensated. For the sake of brief, only the results of horizontal borehole in Pingdingshan Number 1 coal mine are shown in Figure 11. It is clear that the recovery stress measured by all sensing faces in different directions increases gradually to be stable, although the rate of stress recovery decreases with time. According to the analytical results of the relationship between 


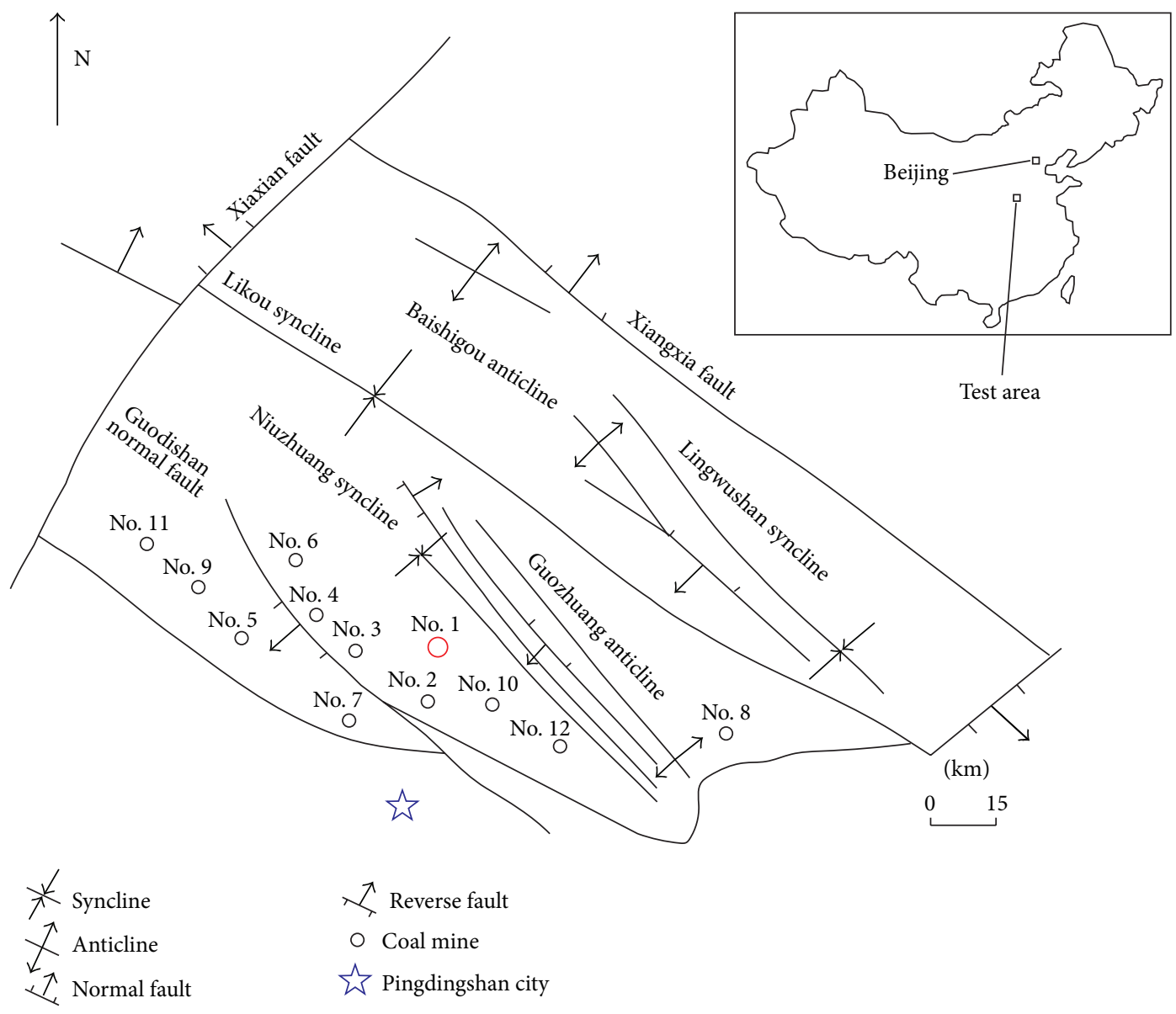

Figure 8: Schematic map of the Pingdingshan coal mine [27].

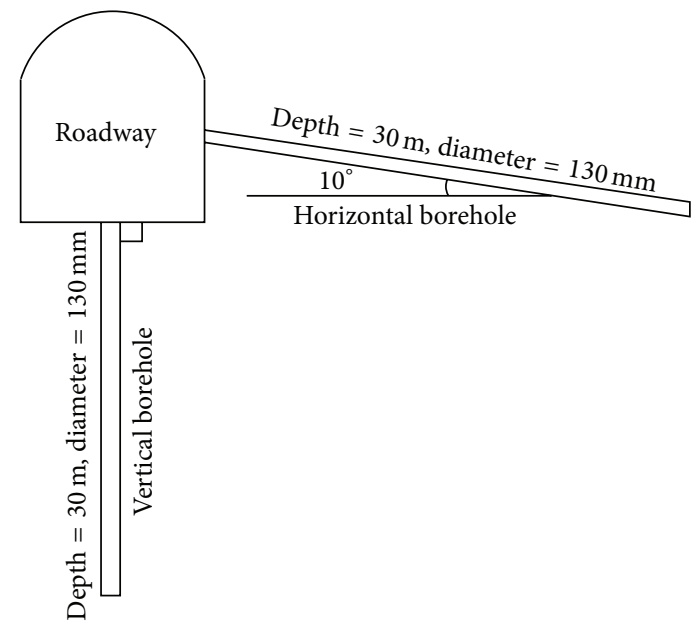

FIGURE 9: Sketch of the borehole layout.

the final recovery stress and initial stress, and the ratio of the initial modulus to the long-term modulus $\left(G_{\text {ini }} / G_{\infty} \approx\right.$ 1.8) from experimental tests, the final recovery ratio can be determined (about 0.45). Then, the initial stresses vertical to each sensing face can be calculated and inserted into the calculation formulation (1) to obtain the stress tensor in local coordinate system, and the principal stress components in global coordinate system can be calculated using coordinate transformation. The results of the magnitude, azimuth, and dip angle of three principal stresses in both horizontal and vertical boreholes in Pingdingshan Number 1 coal mine are listed in Table 2. All the test results show that the orientation of the maximum principal stress $\sigma_{1}$ and the minimum stress $\sigma_{3}$ is approximately in the horizontal plane and that of the intermediate principal stress is nearly vertical.

From Tables 1 and 2, it can be found that the principal stress magnitudes of overcoring vary in a range when selecting different elastic parameters, and the results of RSR method are within this range. The orientations of principal stresses by both overcoring technique and RSR method are drawn in the stereographic projection shown in Figure 11. The dominant orientations of the maximum principal stress are almost the same for both the overcoring technique and RSR method. Pingdingshan region has experienced three obvious tectonic movements in the geologic history: the Indosinian movement during the Triassic period, the Yanshan movement during the Mesozoic period, and the Himalayan movement during the Neozoic period. Accordingly, the direction of the major principle stress in this region has shifted from NE-SW 
TABLE 2: In situ stress magnitudes by RSR method at the horizontal and vertical boreholes.

\begin{tabular}{lccccccccc}
\hline $\begin{array}{l}\text { Borehole } \\
\text { position }\end{array}$ & Magnitude $(\mathrm{MPa})$ & $\sigma_{1}$ & \multicolumn{3}{c}{$\sigma_{2}$} & \multicolumn{3}{c}{$\sigma_{3}$} \\
& Azimuth $\left(^{\circ}\right)$ & Dip $\left(^{\circ}\right)$ & Magnitude $(\mathrm{MPa})$ & Azimuth $\left(^{\circ}\right)$ & Dip $\left(^{\circ}\right)$ & Magnitude $(\mathrm{MPa})$ & Azimuth $\left(^{\circ}\right)$ & Dip $\left(^{\circ}\right)$ \\
\hline Horizontal & 28.21 & 148.87 & 3.78 & 20.50 & 306.64 & 85.92 & 17.80 & 58.77 & 1.54 \\
Vertical & 30.56 & 109.6 & 15.11 & 21.42 & 45.83 & 74.84 & 19.94 & 19.29 & 1.17 \\
\hline
\end{tabular}

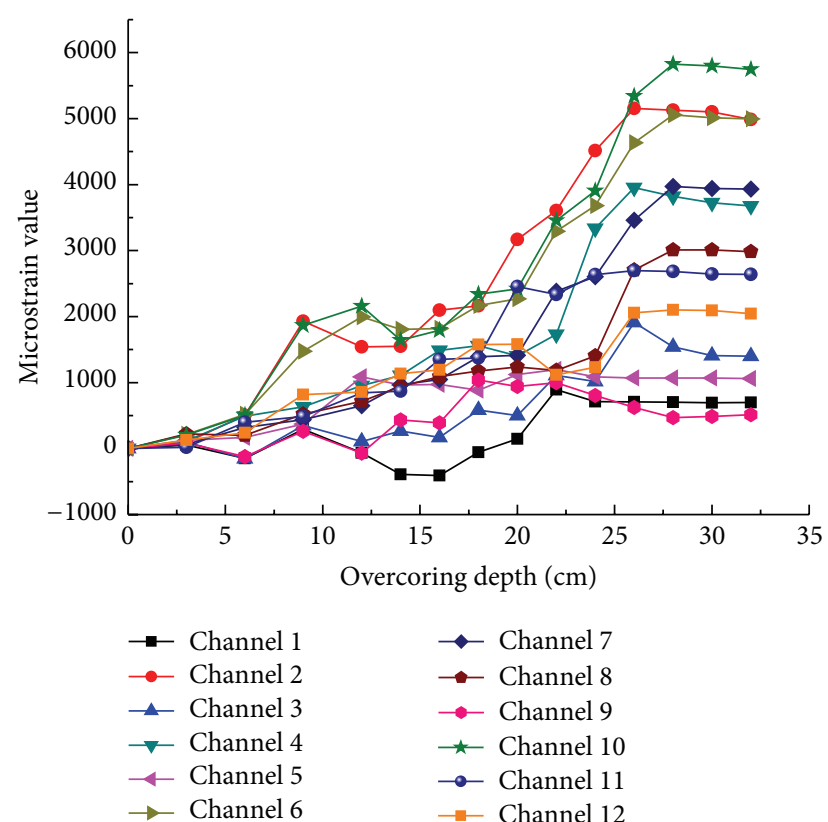

FIGURE 10: Stress relief curves during the overcoring of horizontal borehole at Number 1 coal mine.

to NW-SE, then to approximately EW [30]. Figure 12 shows that the major principle stress directions of testing points are mostly NW-SE and agree with those in the second and third tectonic movements, which reveals that the in situ stress field at present is caused primarily by the latter two tectonic movements. Therefore, it can be said that the result from the RSR method is reliable and the new method for in situ stress measurement can be used to measure rock stresses.

Through the practical application of the overcoring technique and RSR method for in situ stress measurement in Pingdingshan Number 1 coal mine, it can be found that the RSR method may be a maneuverable and effective technique in deep soft rock. The accuracy of elastic parameters has a great influence on the calculated results of stress magnitudes and orientations for overcoring technique. However, the exact elastic parameters of rock mass seem not very necessary for RSR method with respect to conventional methods. In the RSR method, the stress values in different orientations can be measured by the pressure transducer directly and can be used to calculate the stress tensor. The accuracy of stress values is dependent on the calibration factor of the transducer that can be obtained from calibration test. Based on the results of current research [31], the variation of the elastic modulus of surrounding material has little influence on the calibration factor when the elastic modulus ratio of the transducer to

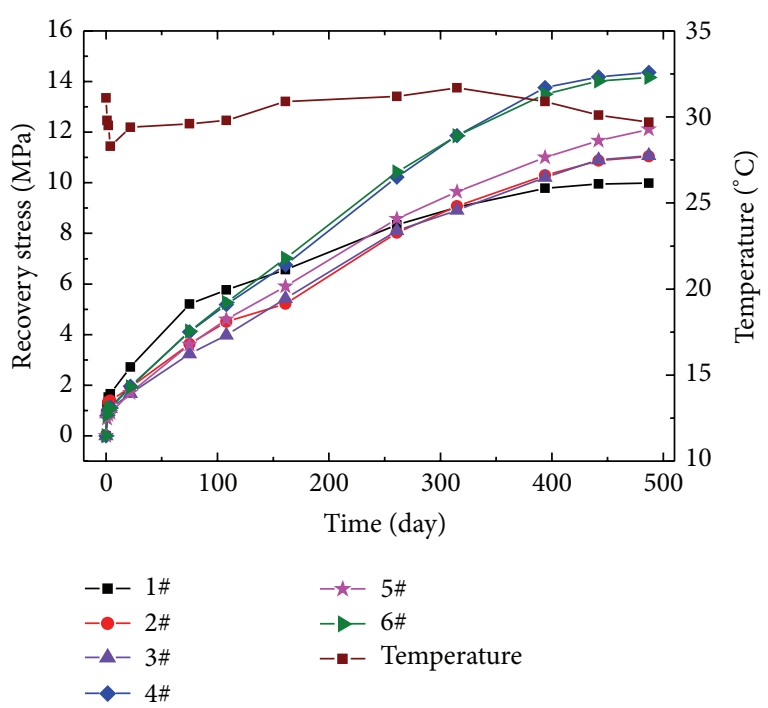

FIGURE 11: Stress recovery process in the horizontal borehole of Pingdingshan Number 1 coal mine.

the surrounding material is large enough. Therefore, the true rock stresses can be inferred by the rough elastic parameters. The measuring errors of RSR method caused by the elastic parameters are less than that of the conventional methods.

For the RSR method, the main requirement of rock mass is good in rheological property. Moreover, the greater the depth of testing site, the better, as the in situ stress at greater depth is generally bigger. In addition, the grouting quality is very important for the RSR method, and the grouting should be accomplished as soon as possible after drilling the hole. The different lateral pressure coefficient may have an influence on the stress values measured by the transducer, which is caused by the difference between the transducer and surrounding material. Through the model test and numerical simulation, it has been found that the measured stresses were linear to the loading stresses for the hydrostatic stress loading, and the measured stresses were linear to both the loading stresses in the same direction and the differential stresses of the other two directions for the nonhydrostatic stress loading [32]. The actual stress values on each sensing face can be deduced by the combination of calibration coefficients and the measured stress values although the lateral pressure coefficient $\lambda$ is unknown.

The transducers that the RSR method uses can be embedded not only in the initial stress area to obtain the magnitudes of original stress, but also in the excavation damage zone to monitor the stress state variation. It has been found that the 


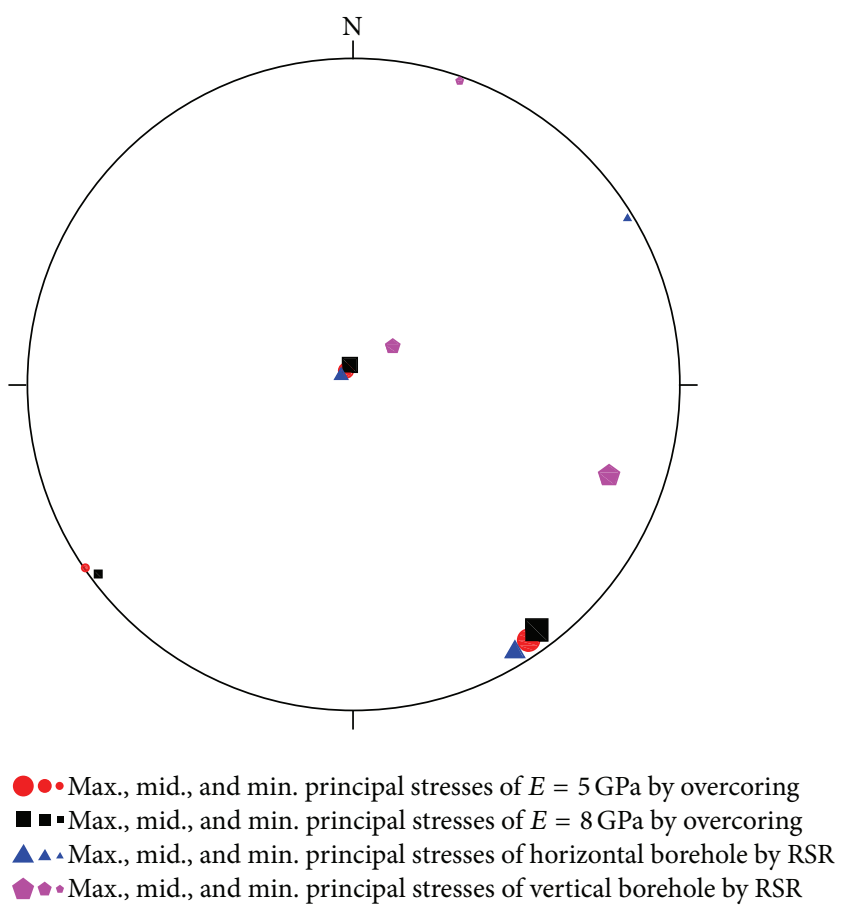

FIGURE 12: Orientations of principal stresses by both overcoring technique and RSR method.

stressmeter that is installed in a specimen under load will pick up the absolute ambient stress in the host when observed over a period of time; concurrently, it responded immediately to an increase of stress generated in the host after the time of its insertion [33].

The RSR method is used to measure the in situ stress based on the rheological behavior of rock; the longer the monitoring time is, therefore, the more precise the results become. However, further research is needed to see how to calculate the stress state of one point through monitoring in a short time for engineering applications.

\section{Conclusions}

For the measurement of the stress in deep soft rock, a RSR method to determine the orientations and magnitudes of $3 \mathrm{D}$ in situ stress is proposed, as well as its test equipment and process, and analytical solutions were derived to analyze the characteristics of this method. Then, the RSR method, as well as overcoring technique, was conducted in Pingdingshan Number 1 coal mine to measure both the in situ stress orientation and magnitude at a depth of $877 \mathrm{~m}$. The results are summarized as follows.

If the rock mass has a better rheological property, the recovery stress measured by the transducer is more close to the initial stress. Moreover, the grouting quality should be ensured that the properties of grouting materials should be close to that of rock masses in actual operation.

These results tested by RSR method and overcoring technique are basically in the same order, which validates that the RSR method is a useful method for deep soft rock masses. The major principal stresses are approximately in the direction of NW-SE, which correlates well with the stress regime of Pingdingshan zone known from the tectonic movement history.

The RSR method can be used to obtain more reliable data when stress relief method cannot be applied in soft or highly jointed rock masses under great depth. Therefore, it can be said that the RSR method may be well suitable for more complicated geological conditions. However, more studies are required to see how to calculate the stress state of one point through monitoring in a short time for engineering applications.

\section{Conflict of Interests}

The authors declare that there is no conflict of interests regarding the publication of this paper.

\section{Acknowledgments}

This work is supported by the National Basic Research Program of China ("973" Program) (Grant no. 2014CB046904) and the National Natural Science Foundation of China (Grant nos. 41130742 and 11302242).

\section{References}

[1] A. Zang and O. Stephansson, Stress Field of the Earth's Crust, Springer Science \& Business Media, 2009.

[2] B. Amadei and O. Stephansson, Rock Stress and Its Measurement, Springer, Dordrecht, The Netherlands, 1997.

[3] C. Ljunggren, Y. Chang, T. Janson, and R. Christiansson, "An overview of rock stress measurement methods," International 
Journal of Rock Mechanics and Mining Sciences, vol. 40, no. 7-8, pp. 975-989, 2003.

[4] R. Corthésy, M. H. Leite, D. E. Gill, and B. Gaudin, "Stress measurements in soft rocks," Engineering Geology, vol. 69, no. 3-4, pp. 381-397, 2003.

[5] R. Ulusay, The ISRM Suggested Methods for Rock Characterization, Testing and Monitoring: 2007-2014, Springer, 2015.

[6] C. Liu, "Distribution laws of in-situ stress in deep underground coal mines," Procedia Engineering, vol. 26, pp. 909-917, 2011.

[7] J. Rutqvist, C.-F. Tsang, and O. Stephansson, "Uncertainty in the maximum principal stress estimated from hydraulic fracturing measurements due to the presence of the induced fracture," International Journal of Rock Mechanics and Mining Sciences, vol. 37, no. 1-2, pp. 107-120, 2000.

[8] C. Ljunggren and G. Raillard, "Rock stress measurements by means of hydraulic tests on pre-existing fractures at Gideå test site, Sweden," International Journal of Rock Mechanics and Mining Sciences \& Geomechanics Abstracts, vol. 24, no. 6, pp. 339-345, 1987.

[9] B. C. Haimson and F. H. Cornet, "ISRM suggested methods for rock stress estimation. Part 3. Hydraulic fracturing (HF) and/or hydraulic testing of pre-existing fractures (HTPF)," International Journal of Rock Mechanics and Mining Sciences, vol. 40, no. 7-8, pp. 1011-1020, 2003.

[10] M. H. Talebi, S. Heidari, M. Moosavi, and M. Rahimi, "In situ stress measurements of two hydropower projects in Iran by hydraulic fracturing method," Arabian Journal of Geosciences, vol. 8, no. 9, pp. 7073-7085, 2015.

[11] M. L. Wu, Y. Q. Zhang, C. T. Liao et al., "Preliminary results of in-situ stress measurements along the Longmenshan fault zone after the Wenchuan $M_{s} 8.0$ earthquake," Acta Geologica SinicaEnglish Edition, vol. 83, no. 4, pp. 746-753, 2009.

[12] B. Amadei, Rock Anisotropy and the Theory of Stress Measurements, Springer, 1983.

[13] P. Thompson, R. Corthesy, and M. Leite, "Rock stress measurements at great depth using the modified doorstopper gauge," in Proceedings of the International Symposium Rock Stress, Japan, K. Sugawara and Y. Obara, Eds., pp. 59-64, AA Balkema, 1997.

[14] G. Della Vecchia, A. Pandolfi, G. Musso, and G. Capasso, "An analytical expression for the determination of in situ stress state from borehole data accounting for breakout size," International Journal of Rock Mechanics and Mining Sciences, vol. 66, pp. 6468, 2014.

[15] M. Seto, D. K. Nag, and V. S. Vutukuri, "In-situ rock stress measurement from rock cores using the acoustic emission method and deformation rate analysis," Geotechnical and Geological Engineering, vol. 17, no. 3-4, pp. 241-266, 1999.

[16] L. Gao, W. Lin, D. Sun, and H. Wang, "Experimental anelastic strain recovery compliance of three typical rocks," Rock Mechanics and Rock Engineering, vol. 47, no. 6, pp. 1987-1995, 2014.

[17] K. Matsuki and K. Takeuchi, "Three-dimensional in situ stress determination by anelastic strain recovery of a rock core," International Journal of Rock Mechanics and Mining Sciences \& Geomechanics Abstracts, vol. 30, no. 7, pp. 1019-1022, 1993.

[18] D. Sun, W. Lin, J. Cui et al., “Three-dimensional in situ stress determination by anelastic strain recovery and its application at the Wenchuan Earthquake Fault Scientific Drilling Hole-1 (WFSD-1)," Science China Earth Sciences, vol. 57, no. 6, pp. 12121220, 2014.
[19] L. Teufel, "Determination of in situ stress from partial anelastic strain recovery measurements of oriented cores from deep boreholes," in Proceedings of the 34th US Rock Mechanics Symposium on Short Course Modern In Situ Stress Measurement Methods, pp. 27-30, June 1993.

[20] Z. Guan, Y. Jiang, and Y. Tanabashi, "Rheological parameter estimation for the prediction of long-term deformations in conventional tunnelling," Tunnelling and Underground Space Technology, vol. 24, no. 3, pp. 250-259, 2009.

[21] S. Wassmann and B. Stöckhert, "Rheology of the plate interface-dissolution precipitation creep in high pressure metamorphic rocks," Tectonophysics, vol. 608, pp. 1-29, 2013.

[22] D. F. Malan, “Time-dependent behaviour of deep level tabular excavations in hard rock," Rock Mechanics and Rock Engineering, vol. 32, no. 2, pp. 123-155, 1999.

[23] D. M. Stefanescu, Handbook of Force Transducers: Principles and Components, Springer Science \& Business Media, 2011.

[24] A. Fahimifar, F. M. Tehrani, A. Hedayat, and A. Vakilzadeh, "Analytical solution for the excavation of circular tunnels in a visco-elastic Burger's material under hydrostatic stress field," Tunnelling and Underground Space Technology, vol. 25, no. 4, pp. 297-304, 2010.

[25] H. N. Wang, Y. Li, Q. Ni, S. Utili, M. J. Jiang, and F. Liu, "Analytical solutions for the construction of deeply buried circular tunnels with two liners in rheological rock," Rock Mechanics and Rock Engineering, vol. 46, no. 6, pp. 1481-1498, 2013.

[26] R. E. Goodman, Introduction to Rock Mechanics, Wiley, New York, NY, USA, 1989.

[27] H. Li, "Major and minor structural features of a bedding shear zone along a coal seam and related gas outburst, Pingdingshan coalfield, Northern China," International Journal of Coal Geology, vol. 47, no. 2, pp. 101-113, 2001.

[28] J. Sjöberg, R. Christiansson, and J. A. Hudson, "ISRM suggested methods for rock stress estimation-part 2: overcoring methods," International Journal of Rock Mechanics and Mining Sciences, vol. 40, no. 7-8, pp. 999-1010, 2003.

[29] X. R. Ge and M. X. Hou, "Principle of in-situ 3D rock stress measurement with borehole wall stress relief method and its preliminary applications to determination of in-situ rock stress orientation and magnitude in Jinping hydropower station," Science China Technological Sciences, vol. 55, no. 4, pp. 939-949, 2012.

[30] Y. Wang, H. Jing, K. Chen, and L. Wei, "Study of distribution regularities and regional division of in-situ stresses for Pingdingshan Mining area," Chinese Journal of Rock Mechanics and Engineering, vol. 33, no. 1, pp. 2620-2627, 2014.

[31] R. Collins, K. Lee, G. Lilly, and R. Westmann, "Mechanics of pressure cells," Experimental Mechanics, vol. 12, no. 11, pp. 514$519,1972$.

[32] Y. Zhu, Q. Liu, J. Jiang, Y. Huang, and Y. Pan, “Measuring performance of three-dimensional pressure sensor in cement mortar block," Chinese Journal of Rock Mechanics and Engineering, vol. 34, pp. 1877-1885, 2015.

[33] D. Skilton, "Behaviour of rigid inclusion stressmeters in viscoelastic rock," International Journal of Rock Mechanics and Mining Sciences \& Geomechanics Abstracts, vol. 8, no. 4, pp. 283289, 1971. 


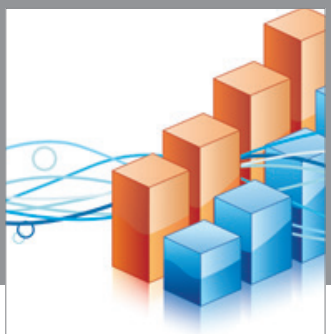

Advances in

Operations Research

vatem alat4

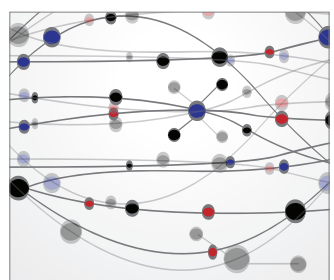

\section{The Scientific} World Journal
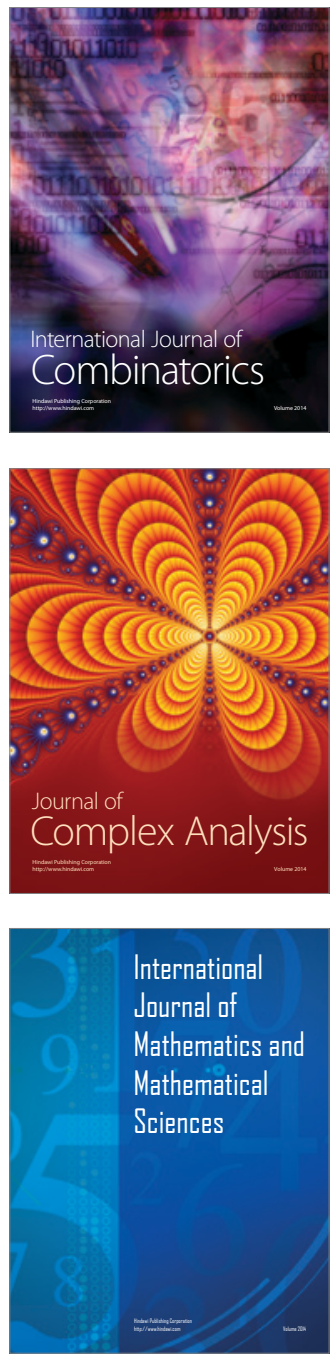
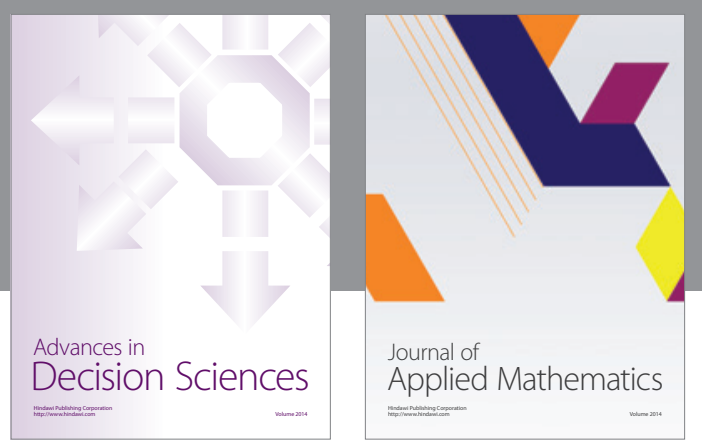

Algebra

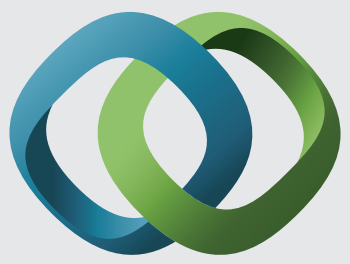

\section{Hindawi}

Submit your manuscripts at

http://www.hindawi.com
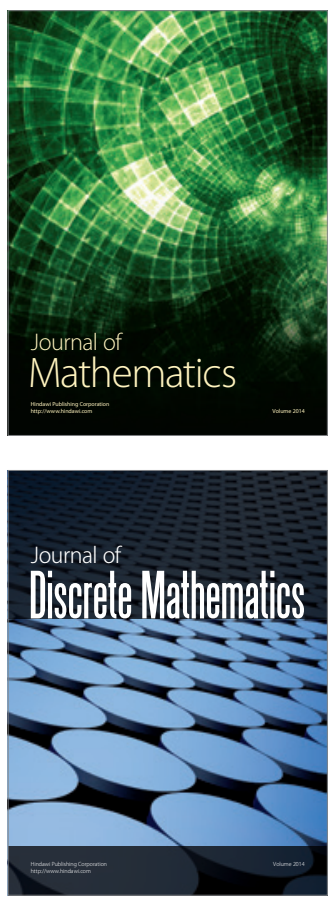

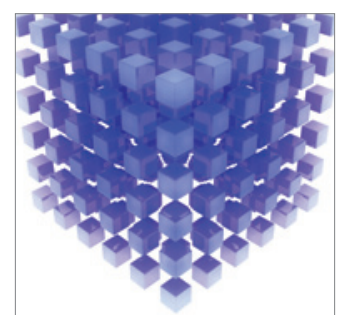

Mathematical Problems in Engineering
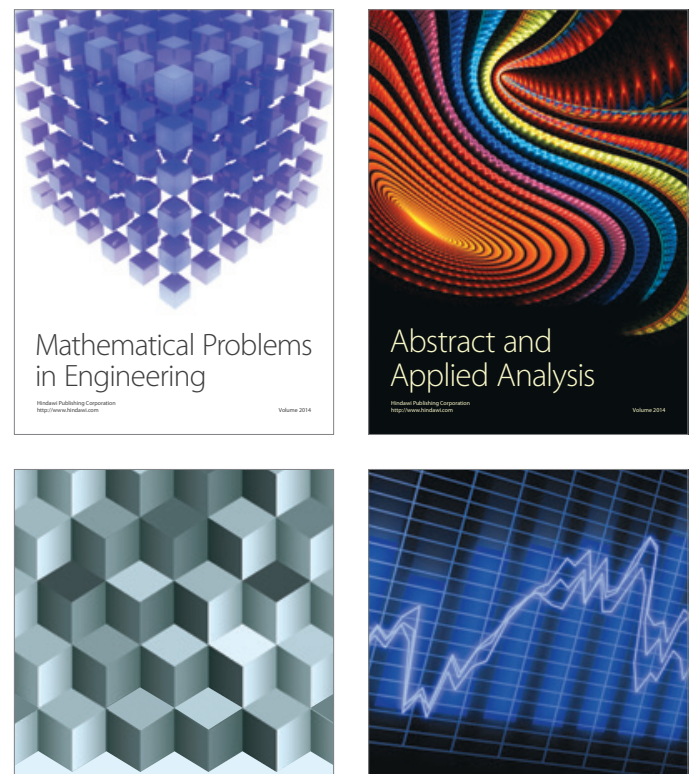

Journal of

Function Spaces

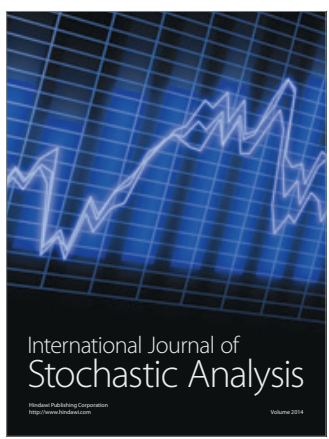

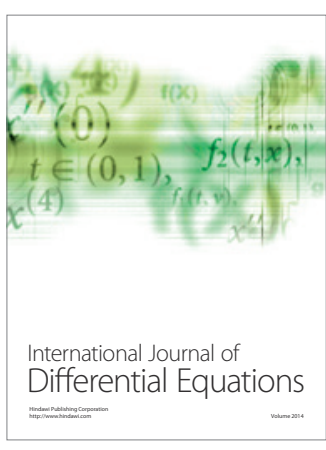
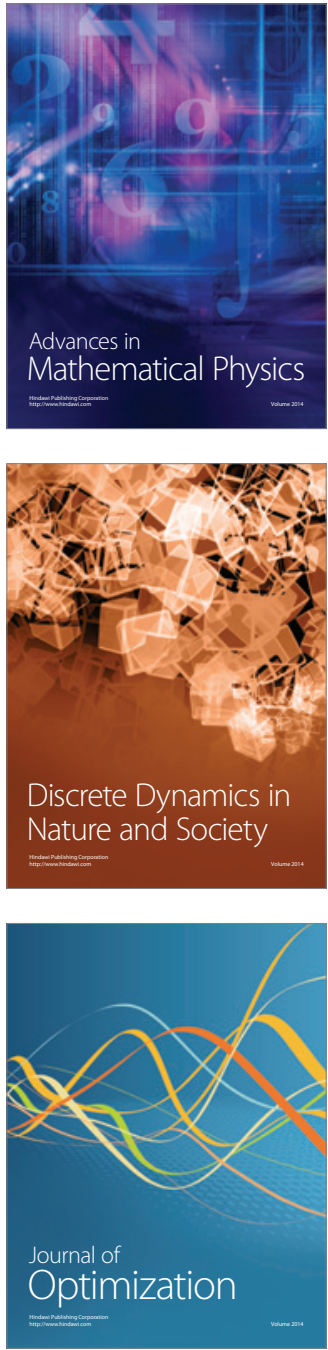